(2) Open Access Full Text Article

\title{
Two cases of $X$-linked retinoschisis with different spectral domain optical coherence tomography findings
}

This article was published in the following Dove Press journal:

Clinical Ophthalmology

21 September 2012

Number of times this article has been viewed

\section{Theodore Leng}

Byers Eye Institute at Stanford, Stanford University School of Medicine, Palo Alto, CA, USA
Correspondence: Theodore Leng Byers Eye Institute at Stanford, Stanford University School of Medicine, 2452 Watson Court, Palo Alto, CA, 94303, USA

$\mathrm{Tel}+\mathrm{I} 6504984264$

Fax +l 8885652640

Email tedleng@stanford.edu
Abstract: Spectral domain optical coherence tomography was used to image the maculae of two brothers who had the diagnosis of X-linked retinoschisis maculopathy. One patient demonstrated a large foveal cyst in one eye and a lamellar macular hole in the fellow eye. The second patient demonstrated small retinal cysts in multiple layers of the retina. Spectral domain optical coherence tomography allowed high-resolution imaging and characterization of the features in $\mathrm{X}$-linked retinoschisis in these patients, and it highlighted the variability of the same genetic disease, even in one family.

Keywords: SD-OCT, XLRS, retina, imaging, maculopathy

\section{Introduction}

$\mathrm{X}$-linked retinoschisis (XLRS) is a bilateral progressive disease of the retina that is likely present at birth and progresses as the child ages. It is associated with a mutation of the XLRS1 gene located on the short arm of the $\mathrm{X}$ chromosome, $\mathrm{Xp} 22,{ }^{1}$ and is clinically characterized by cystoid changes of the fovea arranged in a stellate pattern. ${ }^{2}$ Several publications describing the optical coherence tomography (OCT) characteristics of XLRS have noted different findings for this condition. Splitting in the nerve fiber layer (NFL) attributed to Mueller cell dysfunction was noted on histological studies $^{3}$ and was observed in vivo with OCT by Eriksson et al. ${ }^{4}$ Additionally, groups have described splitting in retinal layers deep to the NFL with OCT. ${ }^{5-7}$

\section{Case reports}

A 13-year-old African-American boy (Case 1) presented for evaluation of decreased vision. The patient's mother reported that the boy had experienced poor vision for many years. His best-corrected visual acuity was 20/200 OD and 20/400 OS with no improvement on manifest refraction or pinhole testing. The fundus (Figure 1) and spectral domain optical coherence tomography (SD-OCT) (Figure 2) exams demonstrated findings consistent with XLRS. The patient was referred to a low vision specialist for evaluation.

The boy's 14-year-old brother (Case 2) was examined and found to have a bestcorrected visual acuity of 20/400 OD and 20/40 OS without improvement on manifest refraction or pinhole testing. The mother reported that this sibling had experienced poor vision for the past 7 years and that his sensory exotropia had also existed for approximately the same time. Fundus (Figure 3) and SD-OCT (Figure 4) exams 


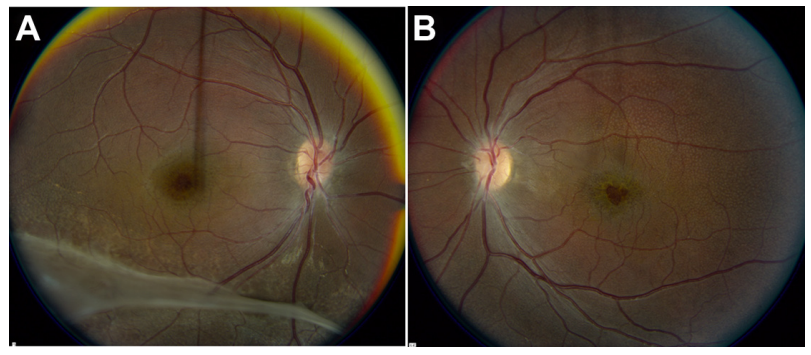

Figure I Color fundus photographs of Case I. The right eye (A) demonstrates a cystic spoke-like appearance to the fovea and the presence of a vitreous veil inferiorly. The left eye (B) demonstrates an area of focal foveal thinning, as well as multiple white dots throughout the macula.

demonstrated findings consistent with XLRS. The patient was also referred to a low vision specialist for evaluation.

Genetic and electrophysiologic testing were offered for these patients; however, the parents deferred these additional exams.

\section{Discussion}

SD-OCT is a powerful technology that has several advantages over time-domain OCT. Although the axial resolution of the two technologies is comparable, the advantage of SD-OCT is in the speed of image acquisition. The result is reduced motion artifact and improved image clarity, allowing clinicians to better delineate retinal structures and pathology. ${ }^{8-10}$

The imaging of patients was performed using an SDOCT instrument with $6 \mu \mathrm{m}$ axial resolution (CirrusOCT ${ }^{\mathrm{TM}}$; Carl Zeiss Meditec, Dublin, CA) with an acquisition speed

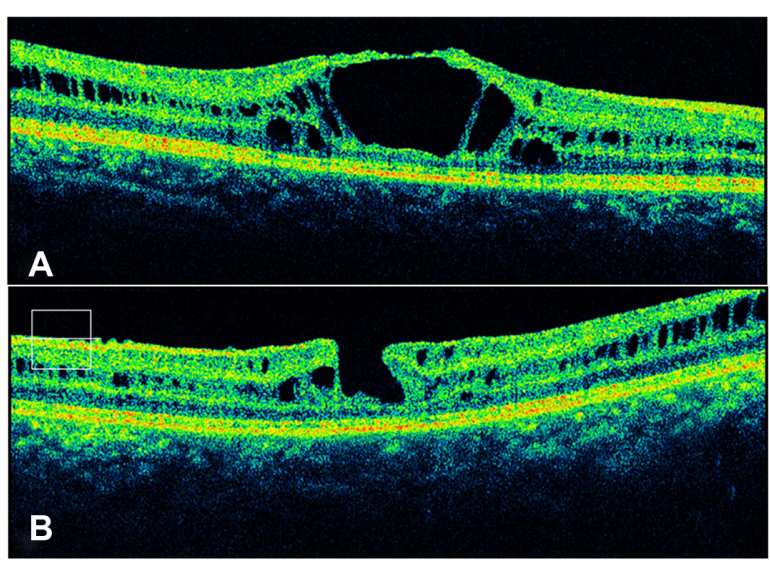

Figure 2 Spectral domain optical coherence tomography images of Case I taken through the center of the fovea. The right eye (A) demonstrates a large central cyst that extends from the nerve fiber layer to the outer retina. Both the right and left (B) eyes demonstrated the presence of cystic spaces and splitting of the retina in multiple layers, including the nerve fiber layer, the inner plexiform layer, and the outer plexiform layer.

Note: The left eye also disclosed a lamellar macular hole and contraction of the internal limiting membrane nasally (consistent with an epiretinal membrane).

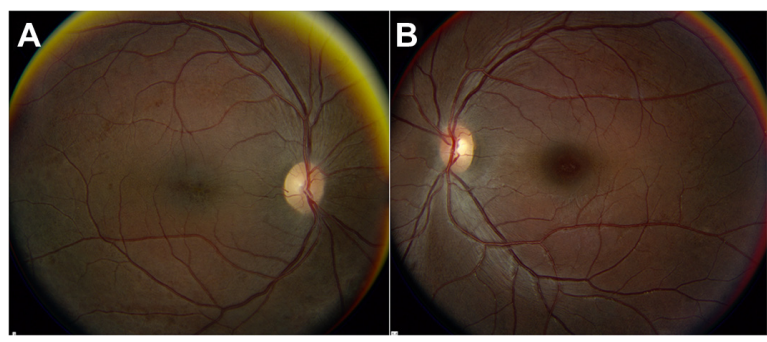

Figure 3 Color fundus photographs of Case 2. The right eye (A) demonstrates a cystic appearance of the fovea. The left eye (B) demonstrates more subtle findings of $X$-linked retinoschisis.

Notes: The foveola appears normal on clinical examination; however, fine cystic lesions are present in the perifoveal area and in the temporal macula.

of approximately 26,000 A-scans per second. Images were acquired using a $6 \mathrm{~mm} \times 6 \mathrm{~mm}$ raster scanning pattern through the macula, centered on the fovea. Each of the horizontal scans consisted of $200 \mathrm{~A}$-scans, and $30 \mu \mathrm{m}$ separated each of 200 horizontal scans through the macula. The entire $6 \mathrm{~mm} \times 6 \mathrm{~mm}$ dataset at a depth of $2 \mathrm{~mm}$ was acquired in approximately 1.5 seconds. In addition, the central macula was imaged using five high-density $6 \mathrm{~mm}$ horizontal B-scans separated by $250 \mu \mathrm{m}$, each consisting of $4096 \mathrm{~A}$-scans, which were acquired in approximately 0.6 seconds.

The detail from the SD-OCT scans was ideal for visualizing the retinal architecture and cystic changes in the eyes with XLRS, thereby allowing for precise identification of the pathologic changes and their location within the structure of the retina. ${ }^{11-13}$

Most likely, the retinal cystic changes associated with XLRS begin to occur shortly after birth, enlarge, and coalesce

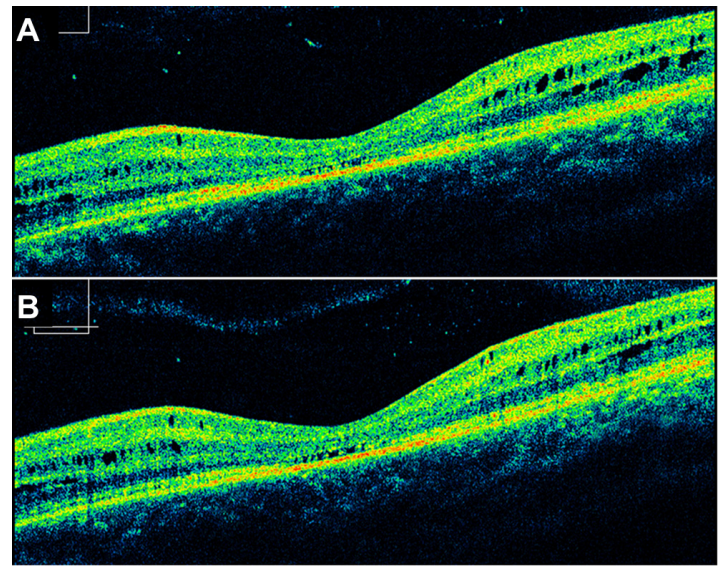

Figure 4 Spectral domain optical coherence tomography analysis of the left eye of Case 2. The right eye demonstrated similar findings as the right eye of Case I (not shown). Horizontal cuts through the left eye taken above (A) and below (B) the fovea demonstrated multiple small cystic spaces in multiple retinal layers without disruption of the overall structure of the retina.

Notes: The inner segment-outer segment junction appears to be discontinuous in areas; however, this likely represents optical shadowing from the anteriorly located cystic spaces. 
in size over time. In early cases, it may not be evident from the clinical dilated fundus exam that any pathology is present. Given the enhanced detail available with SD-OCT, the early retinal changes may be visualized and a diagnosis made sooner in patients suspected to have the disease. An earlier diagnosis results in timely referrals to low vision services and genetic counselors for this macular disease. These two cases also highlight the variability of the same genetic disease, even within the same family.

Furthermore, while the first case had very pronounced findings (a large central cyst that extended from the NFL to the outer retina and a lamellar macular hole), the left eye of the second case had very subtle retinal findings (Figure 3B); and there were no foveal lesions present on exam. However, SD-OCT was able to visualize the early cystic changes associated with XLRS (Figure 4). The enhanced retinal detail that is possible with SD-OCT is not only beneficial to earlier diagnosis, but may also aid in the previously described classification schemes for XLRS. ${ }^{14}$

\section{Disclosure}

The author reports no conflicts of interest in this work.

\section{References}

1. Sauer CG, Gehrig A. Positional cloning of the gene associated with X-linked juvenile retinoschisis. Nat Genet. 1997;17:164-170.

2. Gass JDM. Heredodystrophic disorders affecting the pigment epithelium and retina. In: Stereoscopic Atlas of Macular Diseases. 3rd ed. St Louis, Mo: CV Mosby Co; 1997:235-331.
3. Manschot WA. Pathology of hereditary juvenile retinoschisis. Arch Ophthalmol. 1972;88:131-138.

4. Eriksson U, Larsson E, Holmström G. Optical coherence tomography in the diagnosis of juvenile X-linked retinoschisis. Acta Ophthalmol Scand. 2004;82:218-223.

5. Apushkin MA, Fishman GA, Janowicz MJ. Correlation of optical coherence tomography findings with visual acuity and macular lesions in patients with X-linked retinoschisis. Ophthalmology. 2005;112:495-501.

6. Green JM, Shakin EP. Optical coherence tomography findings in foveal schisis. Arch Ophthalmol. 2004;122:1066-1067.

7. Gao H, Kusumi R, Yung C. Optical coherence tomographic findings in X-linked juvenile retinoschisis. Arch Ophthalmol. 2005;123: 1006-1008.

8. Wojtkowski M, Bajraszewski T, Targowski P, Kowalczyk A. Real-time in vivo imaging by high-speed spectral optical coherence tomography. Opt Lett. 2003;28:1745-1747.

9. Yun SH, Boudoux C, Tearney GJ, Bouma BE. High-speed wavelengthswept semiconductor laser with a polygon-scanner-based wavelength filter. Opt Lett. 2003;28:1981-1983.

10. Nassif N, Cense B, Park BH, et al. In vivo human retinal imaging by ultrahigh-speed spectral domain optical coherence tomography. Opt Lett. 2004;29(5):480-482.

11. Kjellstrom S, Vijayasarathy C, Ponjavic V, Sieving PA, Andreasson S. Long-term 12 year follow-up of X-linked congenital retinoschisis. Ophthalmic Genet. 2010;31:114-125.

12. Gregori NZ, Berrocal AM, Gregori G, et al. Macular spectral-domain optical coherence tomography in patients with $\mathrm{X}$ linked retinoschisis. Br J Ophthalmol. 2009;93:373-378.

13. Gerth C, Zawadzki RJ, Werner JS, Heon E. Retinal morphological changes of patients with X-linked retinoschisis evaluated by Fourier-domain optical coherence tomography. Arch Ophthalmol. 2008;126:807-811.

14. Prenner JL, Capone A, Ciaccia S, Takada Y, Sieving PA, Trese MT. Congenital X-linked retinoschisis classification system. Retina. 2006;26(Suppl 7):S61-S64.
Clinical Ophthalmology

\section{Publish your work in this journal}

Clinical Ophthalmology is an international, peer-reviewed journal covering all subspecialties within ophthalmology. Key topics include: Optometry; Visual science; Pharmacology and drug therapy in eye diseases; Basic Sciences; Primary and Secondary eye care; Patient Safety and Quality of Care Improvements. This journal is indexed on

Submit your manuscript here: http://www.dovepress.com/clinical-ophthalmology-journal

\section{Dovepress}

PubMed Central and CAS, and is the official journal of The Society of Clinical Ophthalmology (SCO). The manuscript management system is completely online and includes a very quick and fair peer-review system, which is all easy to use. Visit http://www.dovepress.com/ testimonials.php to read real quotes from published authors. 